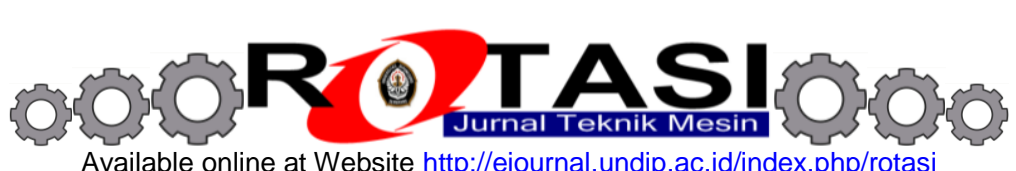

Available online at Website http://ejournal.undip.ac.id/index.php/rotasi

\title{
ANALISA KINEMATIK, DINAMIK DAN METODE GERAK KAKI MODEL SNOOPER HEXAPOD ROBOT
}

\author{
*Munadi, Ismoyo Haryanto, Toni Prahasto \\ Jurusan Teknik Mesin, Fakultas Teknik, Universitas Diponegoro \\ Jl. Prof. Sudharto, SH, Tembalang, Semarang 50275 \\ *E-mail: munadi@undip.ac.id
}

\begin{abstract}
This article presents how to make a model of snooper hexapod robot as a legged robot which is inspired by the spider. This model robot is used for monitoring systems of an industrial area. We design an hexapod robot that consists of 18 dof, which it used acrylic as a base material, servomotor as a driver and an ATmega 128 as microcontroller. We start to make a mechanical design of a snooper hexapod robot construction. Furthermore, kinematics and dynamics analysis of hexapod robot is discussed using Matlab from the control point of view. The objective of kinematic analysis is to determine the kinematic quatities such as displacements, velocities, and accelerations of the elements of model robot when the input motion is given. It establishes the relationship between the motions of various components of the link. The dynamics analysis will inform a torque at the joint ankle hexapod robot using modeling Matlab Simmechanics. The model of hexapod robot is used for monitoring systems so called snooper hexapod will be designed and manufactured so have the required capabilities as a surveillance robot that is able to reach the difficult area and can transmit visual information to the operators who control it. Analysis is done on the robot motion algorithm on three kinds of methods of walk (one wave, two wave, and tripod) with few parameters specified.
\end{abstract}

Keywords: snooper hexapod robot, kinematic, dynamic, motion analysis

\section{PENDAhuluan}

Dengan perkembangan teknologi yang semakin pesat, beberapa lembaga penelitian telah mencoba mengembangkan model robot yang dapat berjalan (mobile). Hal tersebut diyakini bahwa kemajuan yang signifikan pada suatu hari akan dicapai dengan berhasilnya diciptakan model robot yang dapat bekerja dengan berjalan, tidak hanya model robot menyerupai manusia saja. Robot yang diciptakan tentunya berfungsi untuk mempermudah atau membantu tugas manusia, khususnya untuk melaksanakan tugas yang tidak dapat dilakukan oleh manusia secara langsung dengan dasar pertimbangan waktu sampai dengan keamanan. Oleh karena kekomplekan sistem robot yang akan diciptakan, tentunya penelitian yang dilakukan tidak hanya berbekal pada pengetahuan robotika saja, namun kombinasi dari beberapa teknologi lainnya juga diperlukan, antara lain ilmu desain, mekanika, elektronik, dan kontrol [1].

Dalam aplikasinya, robot yang dapat berjalan atau disebut mobile robot harus mampu menjangkau tempat atau area sulit terlebih berbahaya jika dijangkau manusia secara langsung, misal untuk mengintai markas teroris. Oleh sebab itu, untuk bisa menjangkau medan yang sulit, mobile robot jenis robot berkaki (legged) lebih aman dalam melewati medan yang bervariasi dibandingkan robot beroda (wheel). Selanjutnya, hexapod robot merupakan salah satu mobile robot yang dapat berjalan dengan menggunakan enam kaki yang dapat dimanfaatkan untuk menjangkau tempat atau area yang sulit atau bahkan tidak mungkin untuk dapat dijangkau menggunakan mobile robot berroda. Sehingga dengan kemampuannya melintasi medan yang bervariasi maka hexapod robot lebih sering digunakan dibanding jenis yang lain.

Pada perkembangan selanjutnya, hexapod robot dikembangkan dengan dilengkapi kamera dan gripper. Kamera digunakan untuk inspeksi atau monitoring suatu area. Area sebagai objek yang dimonitor biasanya area berbahaya sehingga dapat memberikan data informasi ke home base. Sedangkan gripper digunakan untuk menaruh atau mengambil sebuah objek yang berbahaya. Selain untuk area berbahaya, hexapod robot pada kondisi yang aman juga dapat digunakan untuk proses investigasi maupun monitoring kondisi suatu area sebagai komponen mobile security monitoring systems [2].

Pada penelitian ini, model snooper hexapod robot akan dibuat untuk digunakan dalam tugas monitoring keamanan sebuah area sebagai sebuah unit mobile security monitoring systems. Hal ini dilatarbelakangi adanya beberapa kejadian pada area industri dimana sering terjadi kehilangan barang khususnya pada malam hari walaupun sudah ada tenaga keamanan dan beberapa CCTV yang dipasang pada beberapa lokasi. Tentunya faktor manusia memiliki keterbatasan dalam memonitor keamanan dengan jangka waktu 24 jam. Model hexapod robot yang akan dirancang akan dilengkapi dengan kamera yang dapat mengirimkan informasi visual kepada operator yang mengendalikannya di pos keamanan (home base) baik keadaan pagi, siang terlebih malam hari. Model hexapod robot akan menggunakan servo motor yang bersuara lebih halus agar tidak menimbulkan suara gaduh saat digunakan. Hexapod robot dirancang dengan menggunakan software $\mathrm{CAD}$, dan tentunya akan dianalisa segi kinematik baik forward dan inverse kinematic serta analisa dinamik dengan menggunakan MATLAB/Simmechanic. Untuk analisa algoritma gerak robot didasarkan pada tiga macam metode jalan yaitu one wave, two wave, dan tripod [3]. Untuk 
pemprograman dilakukan dengan compiler CV-AVR dan menggunakan bahasa pemprograman C. Sedangkan untuk pembuatan user interface menggunakan microsoft visual studio 2010a.

\section{PEMODELAN SNOOPER HEXAPOD ROBOT}

Untuk pendesaian model hexapod robot menggunakan salah satu softaware CAD yaitu SolidWorks yang hasilnya ditunjukkan pada Gambar 1.

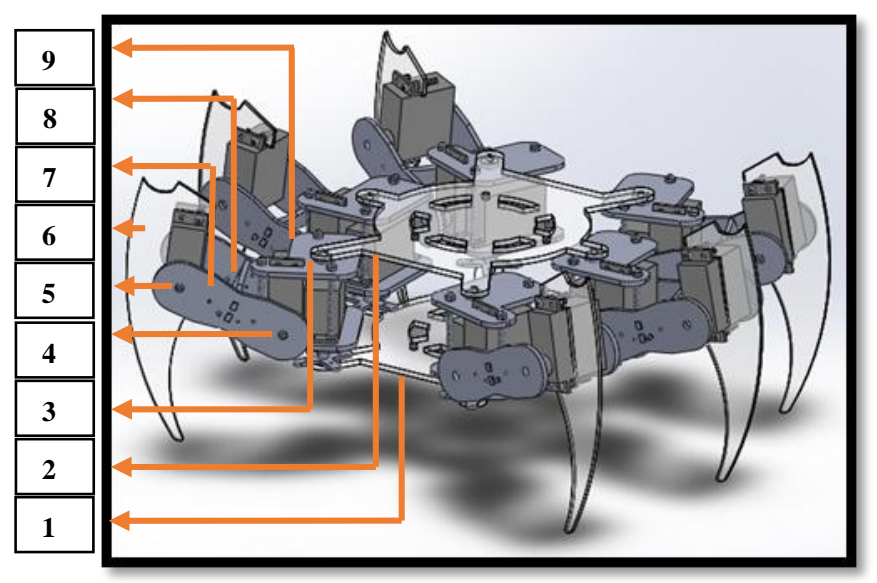

Gambar 1. Desain model hexapod robot.

Ketengan Gambar 1:

$\begin{array}{ll}\text { 1: Body bawah } & \text { 6: Tibia } \\ \text { 2: Body atas } & \text { 7: Femur } \\ \text { 3: Joint } 3 & \text { 8: penguat femur } \\ \text { 4: Joint } 2 & 9: \text { Coxa } \\ \text { 5: Joint } 1 & \end{array}$

Untuk sistem elektronik model hexapod robot ini terdiri atas beberapa komponen elektronika. Beberapa komponen elektronika tersebut adalah mikrokontroler Atmega 128, SPC servo controller, servomotor, wireless modul, wireless camera module, regulator, dan power supply. Komponen-kompoenen tersebut disusun untuk membentuk sebuah diagram desain hardware model hexapod robot yang ditunjukkan pada Gambar 2.



Gambar 2. Desain hardware elektronik hexapod robot

Selanjutnya, agar dapat berkomunikasi antar komponen yang digunakan untuk membuat model hexapod robot, maka dibutuhkan desain komunikasi software dan hardware sehingga masing-masing komponen memiliki andil berperan dalam fungsinya sebagai model snooper hexapod robot. Adapun skema desain komunikasi software dan hardware ditunjukkan pada Gambar 3. 


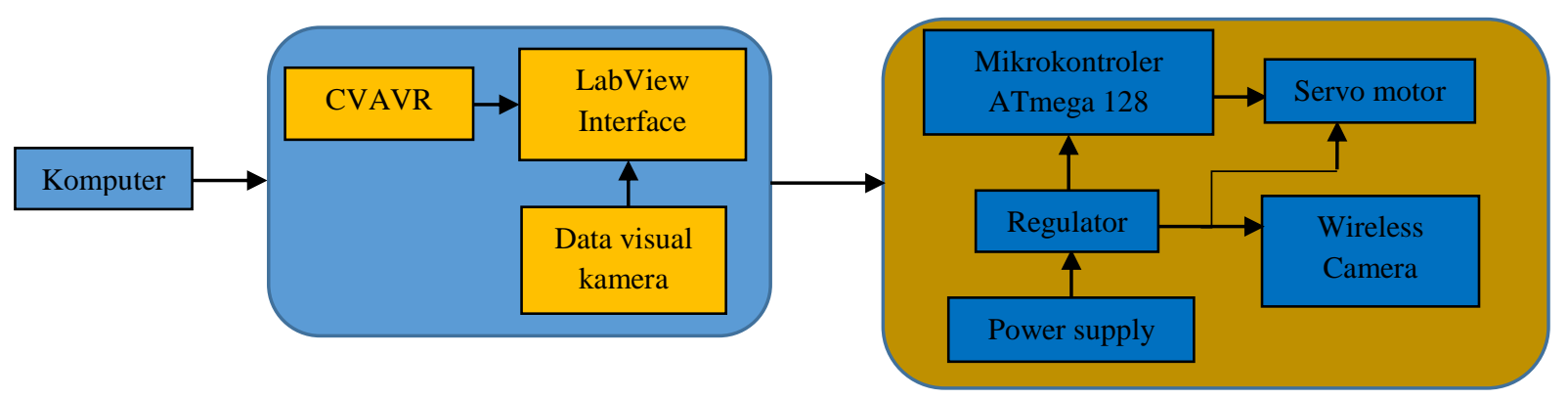

Gambar 3. Skema desain komunikasi software dan hardware

\section{HASIL DAN PEMBAHASAN}

\subsection{Forward dan Inverse Kinematics}

Kita akan menganalisa forward dan inverse kinematics model hexapod robot yang kita buat. Untuk memudahkan dalam perhitungan, kita akan menggunakan alat bantu software MATLAB dan akan kita verfifikasi menggunakan software RoboAnalyzer. Bagian yang akan dianalisa adalah sampling satu kaki hexapod robot yang ditunjukkan pada Gambar 4 dimana masing-masing koordinat frame kita tempatkan pada joint.

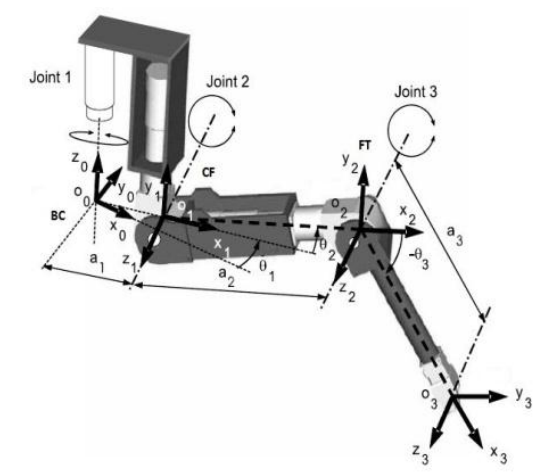

Gambar 4. Koordinat frames satu kaki hexapod robot [4].

Setelah menentukan koordinat frames maka dapat ditentukan Denavit-Hartenberg (DH) parameter dari link kaki hexapod robot yang ditunjukkan pada Tabel 1. Berdasarkan DH Parameter pada Tabel 1 tersebut, maka dapat ditentukan transformasi link dari kaki hexapod robot dengan persamaan berikut [5] :

Tabel 1. DH Parameter

\begin{tabular}{|c|c|c|c|c|}
\hline (Link) & $\boldsymbol{\alpha}_{i-1}$ & $\boldsymbol{\alpha}_{i-1}$ & $\mathrm{~d}_{\mathrm{i}}$ & $\theta_{i}$ \\
\hline 1 & $90^{0}$ & $\mathrm{a}_{1}$ & 0 & $\theta_{1}$ \\
2 & $0^{0}$ & $\mathrm{a}_{2}$ & 0 & $\theta_{2}$ \\
3 & $0^{0}$ & $\mathrm{a}_{3}$ & 0 & $\theta_{3}$ \\
\hline
\end{tabular}

$$
{ }_{i}^{i-1} T=\left[\begin{array}{cccc}
\cos \theta_{i} & -\sin \theta_{i} \cos \alpha_{i} & \sin \theta_{i} \sin \alpha_{i} & a_{i} \cos \theta_{i} \\
\sin \theta_{i} & \cos \theta_{i} \cos \alpha_{i} & -\cos \theta_{i} \sin \alpha_{i} & a_{i} \sin \theta_{i} \\
0 & \sin \alpha_{i} & \cos \alpha_{i} & d_{i} \\
0 & 0 & 0 & 1
\end{array}\right]
$$

Untuk menguji forward kinematic, maka kita tentukan nilai DH parameter yang ditabelkan pada Tabel 2 khususnya pada panjang link sesuai kenyataannya dan sudut putar yang kita asumsikan. Dan berikut merupakan hasil perhitungan dari penyelesaian persamaan transformasi link dengan menggunakan MATLAB :

Tabel 2. DH parameter nilai dari desain hexapod robot

\begin{tabular}{|c|c|c|c|c|}
\hline (Link) & $\alpha_{i-1}$ & $\alpha_{i-1}$ & $\mathrm{~d}_{\mathrm{i}}$ & $\theta_{i}$ \\
\hline 1 & $90^{0}$ & 19 & 0 & 45 \\
\hline 2 & $0^{0}$ & 63 & 0 & 30 \\
\hline 3 & $0^{0}$ & 122,5 & 0 & -100 \\
\hline
\end{tabular}

$$
{ }^{0} T_{3}=\left[\begin{array}{cccc}
0,241 & 0,664 & 0,707 & 81,640 \\
0,241 & 0,664 & -0,707 & 81,640 \\
-0,939 & 0,342 & 0 & -83,612 \\
0 & 0 & 0 & 1,0000
\end{array}\right]
$$

Setelah penyelesaian menggunakan MATLAB maka dilakukan verifikasi pada software RoboAnalyzer yang ditunjukkan dengan Gambar 5. 


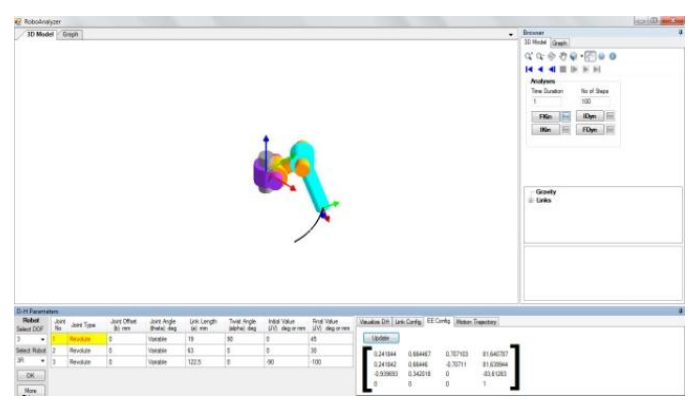

Gambar 5. Hasil verifikasi RoboAnalyzer

Untuk lebih meyakinkan, maka hasil verifikasi melalui perhitungan MATLAB dan memverifikasi dengan RoboAnalyzer, maka dilanjutkan dengan pengujian secara langsung pada model hexapod robot yang ditunjukkan pada Gambar 6, sedangkan hasil keseluruhan ditabelkan pada Tabel 3.

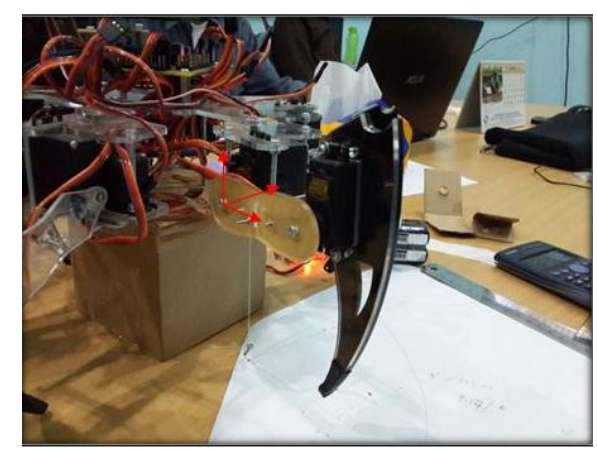

Tabel 3. Hasil analisa forward kinematics

Gambar 6. Posisi awal kaki hexapod robot

\begin{tabular}{|c|c|c|c|c|}
\hline \multirow{2}{*}{ Posisi } & \multicolumn{3}{|c|}{ Hasil } & Error \\
\cline { 2 - 4 } & $\begin{array}{c}\text { Matlab } \\
(\mathrm{mm})\end{array}$ & $\begin{array}{c}\text { RoboAnalyzer } \\
(\mathrm{mm})\end{array}$ & $\begin{array}{c}\text { Pengujian } \\
(\mathrm{mm})\end{array}$ & $(\%)$ \\
\hline $\mathrm{P}_{\mathrm{x}}$ & 81 & 81 & 78 & 3,7 \\
\hline $\mathrm{P}_{\mathrm{y}}$ & 81 & 81 & 86 & 6,2 \\
\hline $\mathrm{P}_{\mathrm{z}}$ & -83 & -83 & $-87,5$ & 5,4 \\
\hline
\end{tabular}

Kemudian dilanjutkan analisa inverse kinematics yang menggunakan perhitungan Matlab dan RoboAnalyzer. Pada Gambar 7 menunjukkan hasil perhitungan inverse kinematics dengan menggunakan RoboAnalyzer. Nilai parameter end-effector didapat dari analisa sebelumnya yaitu forward kinematics. Setelah memasukkan parameter selanjutnya maka hasil lengkap inverse kenematics ditabelkan pada Tabel 4.

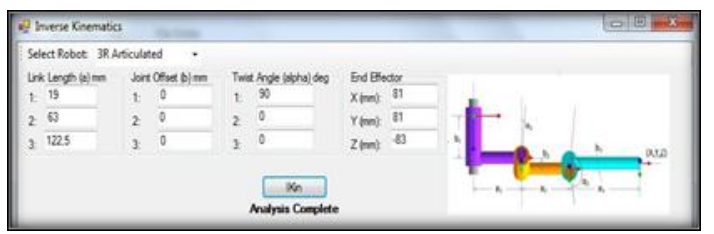

Tabel 4. Hasil analisa inverse kinematics

\begin{tabular}{|c|c|c|c|c|}
\hline $\begin{array}{c}\text { Sudut } \\
\text { (Theta) }\end{array}$ & $\begin{array}{c}\text { Matlab } \\
(\mathrm{deg})\end{array}$ & $\begin{array}{c}\text { RoboAnalyzer } \\
(\mathrm{deg})\end{array}$ & $\begin{array}{c}\text { Pengujian } \\
(\mathrm{deg})\end{array}$ & $\begin{array}{c}\text { Error } \\
(\%)\end{array}$ \\
\hline$\theta_{1}$ & 45 & 45 & 41,1 & 8,7 \\
\hline$\theta_{2}$ & 30,8 & 30,8 & 29,8 & 3,2 \\
\hline$\theta_{3}$ & -101 & -101 & $-105,7$ & 4.6 \\
\hline
\end{tabular}

Gambar 7. Parameter pada kolom inverse kinematics

\subsection{Forward dan Inverse Dynamics}

Berikutnya adalah analisa inverse dynamics dan forward dynamics dengan menggunakan Matlab Simmechanics. Dalam analisa ini yang digunakan adalah satu kaki snooper hexapod robot. Untuk penyelesaian menggunakan persamaan polinomial order 5 sebagai berikut [6].

$$
\begin{aligned}
& \theta_{1}(t)=a_{1} t^{5}+a_{2} t^{4}+a_{3} t^{3}+a_{4} t^{2}+a_{5} t+a_{6} ; \\
& \theta_{2}(t)=b_{1} t^{5}+b_{2} t^{4}+b_{3} t^{3}+b_{4} t^{2}+b_{5} t+b_{6} ; \\
& \theta_{3}(t)=c_{1} t^{5}+c_{2} t^{4}+c_{3} t^{3}+c_{4} t^{2}+c_{5} t+c_{6} ;
\end{aligned}
$$

Dengan menurunkan persamaan diatas maka akan mendapatkan nilai kecepatan dan percepatan awal dari 3 link pada satu kaki hexapod robot. Berikut adalah data panjang setiap link dari model hexapod robot:

$L_{1}=19 \mathrm{~mm}=0,019 \mathrm{~m} ; \quad L_{2}=63 \mathrm{~mm}=0,063 \mathrm{~m} ; \quad L_{3}=122,5 \mathrm{~mm}=0,1225 \mathrm{~m} ;$ 
Selanjutnya untuk menyelesaikan persamaan dengan menggunakan posisi sudut awal dan akhir berdasarkan analisa forward kinematics pada RoboAnalyzer, dan berikut ini data-data yang diperlukan:

$$
\begin{aligned}
& \theta_{1}(t=0)=0^{\circ} ; \\
& a_{6}=\theta_{1}(0)=0 * p i / 180=0 \mathrm{rad} ; \\
& \theta_{2}(t=0)=0^{\circ} \text {; } \\
& \theta_{3}(t=0)=-90^{\circ} \text {; } \\
& b_{6}=\theta_{2}(0)=0 * p i / 180=0 \mathrm{rad} ; \\
& c_{6}=\theta_{3}(0)=-90 * \mathrm{pi} / 180=-1,571 \mathrm{rad} \text {; } \\
& \dot{\theta}_{1}(t=0)=a_{5}=0 \text {; } \\
& \ddot{\theta}_{1}(t=0)=2 a_{4}=0 ; a_{4}=0 \text {; } \\
& \dot{\theta}_{2}(t=0)=b_{5}=0 \text {; } \\
& \ddot{\theta}_{2}(t=0)=2 b_{4}=0 ; b_{4}=0 \text {; } \\
& \dot{\theta}_{3}(t=0)=c_{5}=0 \text {; } \\
& \ddot{\theta}_{3}(t=0)=2 c_{4}=0 ; c_{4}=0 ; \\
& \theta_{1}(t f)-\theta_{1}(t=0)=a_{1} t^{5}+a_{2} t^{4}+a_{3} t^{3} ; \\
& \theta_{2}(t f)-\theta_{2}(t=0)=b_{1} t^{5}+b_{2} t^{4}+b_{3} t^{3} ; \\
& \theta_{3}(t f)-\theta_{3}(t=0)=c_{1} t^{5}+c_{2} t^{4}+c_{3} t^{3}
\end{aligned}
$$

Pada analisa ini kita misalkan sudut terakhir yang ingin dijangkau kita tentukan, antara lain:

$\theta_{1}(t f)=45^{\circ}, \quad \theta_{2}(t f)=30^{\circ}, \quad \theta_{3}(t f)=-100^{\circ}$.

Demikian juga kita harus menentukan nilai kecepatan dan percepatan akhir, kemudian hubungan persamaan di atas dapat diubah dalam bentuk matrik seperti persamaan dibawah ini:

$$
\begin{aligned}
& {\left[\begin{array}{ccc}
t^{5} f & t^{4} f & t^{3} f \\
5 t^{4} f & 4 t^{3} f & 3 t^{2} f \\
20 t^{3} f & 12 t^{2} f & 6 t f
\end{array}\right] *\left[\begin{array}{l}
a_{1} \\
a_{2} \\
a_{3}
\end{array}\right]=\left[\begin{array}{c}
\theta_{1}(t f)-\theta_{1}(0) \\
0 \\
0
\end{array}\right]\left[\begin{array}{ccc}
t^{5} f & t^{4} f & t^{3} f \\
5 t^{4} f & 4 t^{3} f & 3 t^{2} f \\
20 t^{3} f & 12 t^{2} f & 6 t f
\end{array}\right] *\left[\begin{array}{l}
b_{1} \\
b_{2} \\
b_{3}
\end{array}\right]=\left[\begin{array}{c}
\theta_{2}(t f)-\theta_{2}(0) \\
0 \\
0
\end{array}\right]} \\
& {\left[\begin{array}{ccc}
t^{5} f & t^{4} f & t^{3} f \\
5 t^{4} f & 4 t^{3} f & 3 t^{2} f \\
20 t^{3} f & 12 t^{2} f & 6 t f
\end{array}\right] *\left[\begin{array}{c}
c_{1} \\
c_{2} \\
c_{3}
\end{array}\right]=\left[\begin{array}{c}
\theta_{3}(t f)-\theta_{3}(0) \\
0 \\
0
\end{array}\right]}
\end{aligned}
$$

Persamaan-persamaan tersebut lalu diselesaikan dalam Matlab selanjutnya di save dengan nama robot_motion_2013.m lalu di-run yang akan menghasilkan trajectory dari satu kaki hexapod robot seperti yang ditunjukkan pada Gambar 8. Setelah grafik trajectory didapat maka akan dapat ditunjukkan grafik posisi, kecepatan dan percepatan pada setiap link sepeti pada Gambar 9.

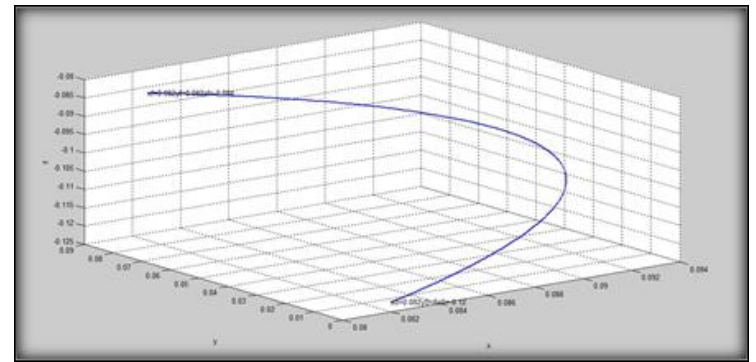

Gambar 8. Trajectory satu kaki model snooper hexapod robot

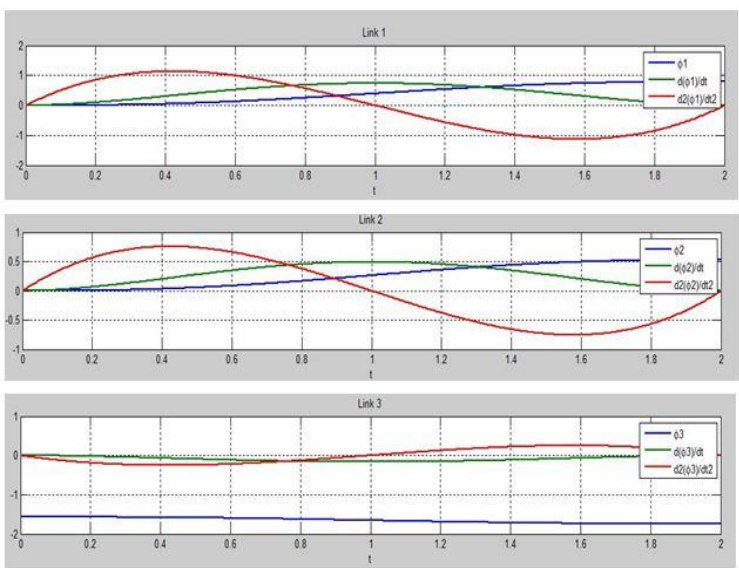

Gambar 9. Grafik posisi, kecepatan dan percepatan

Selain dengan Matlab, analisa inverse dynamics dapat dilakukan dengan toolbox Simmechanics dengan memasukkan parameter masa setiap link berikut ke dalam blok diagram Simmechanics seperti pada Gambar 10. Lalu save dengan nama triple_joint_forward_2013.mdl. Kita juga harus menentukan massa dari masing-masing link.

$m_{1}=13,59 \mathrm{gr}=0.01359 \mathrm{~kg} ; m_{2}=14,12 \mathrm{gr}=0.01412 \mathrm{~kg} ; m_{3}=8.21 \mathrm{gr}=0.00821 \mathrm{~kg}$; 


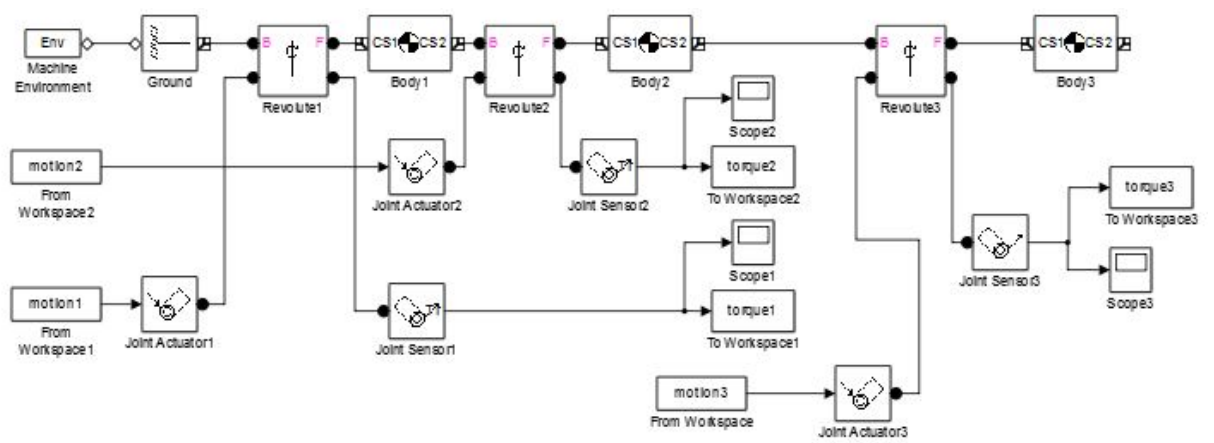

Gambar 10. Diagram blok inverse dynamics

Langkah selanjutnya adalah membuat diagram blok untuk forward dynamics yang ditunjukkan pada Gambar 11 dan save dengan nama triple_joint_forward_2013.mdl.

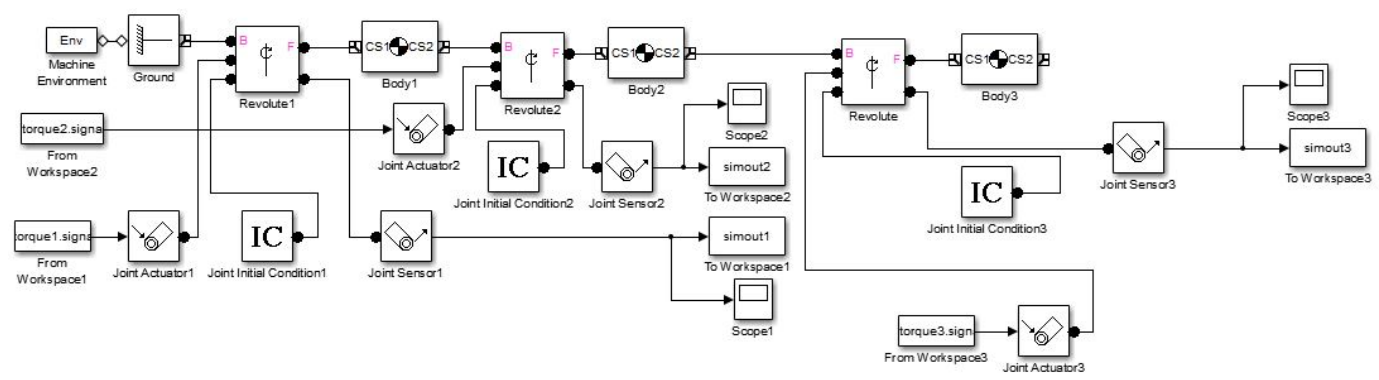

Gambar 11. Diagram blok forward dynamics

Untuk menyelesaikan model Simmechanics ini berturut-turut dengan cara run robot_motion_2013.m lalu triple_joint_inverse_2013.mdl kemudian triple_joint_forward_2013.mdl, selanjutnya kembali ke robot_motion_2013.m. Setelah di-running, dihasilkan grafik fungsi posisi, kecepatan dan percepatan dari masingmasing link yang ditunjukkan pada Gambar 12, serta grafik torsi yang ditunjukkan pada Gambar 13.



Gambar 12. Grafik simulasi Simmechanics



Gambar 13. Grafik torsi setiap link

Dengan pemodelan dalam MatLab Simmechanics, menghasilkan grafik lintasan terhadap waktu dalam sumbu x, $\mathrm{y}$, dan z serta grafik torsi yang dihasilkan dari ketiga joint kaki snooper hexapod robot, dengan nilai torsi puncak linkl= 1,01 Kg.cm pada 0,42 sekon, link2=0,81 Kg.cm pada 0,4 sekon, dan link3=0,234 Kg.cm pada 1,58 sekon.

\subsection{Pengujian Kecepatan}

Pada pengujian kecepatan, sampling dilakukan oleh model hexapod robot dengan melintasi lintasan sepanjang $100 \mathrm{~cm}$ dimana gerakan kaki dibedakan tiga jenis, yaitu one wave, two wave dan tripod. One wave maksudnya kaki bergerak secara satu persatu dimulai dari kaki paling belakang, kemudian diulang oleh sisi yang lainnya. Two wave maksudnya gerakan yang dihasilkan dua kaki yang diangkat. Sedangkan tripod terdiri dari kaki depan dan kaki belakang serta kaki tengah pada sisi lainnya dimana untuk setiap tripod, kaki diangkat, diturunkan, dan digerakkan maju mundur secara bersamaan. Untuk detailnya ditunjukkan pada Gambar 14 [7]. 


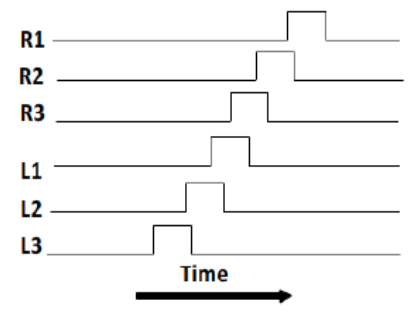

(a)

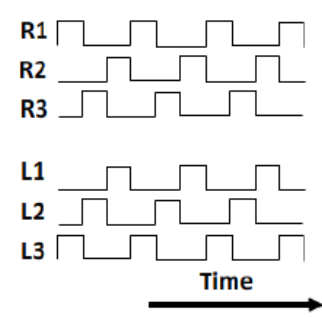

(b)

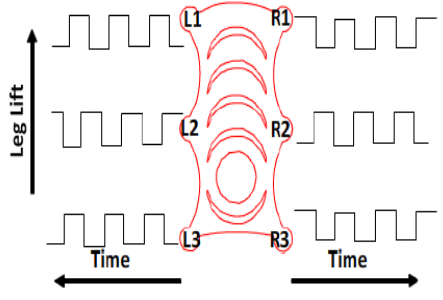

(c)

Gambar 14. Skema one wave (a) two wave (b), dan tripod (c)

Berdasarkan tiga skema pengujian kecepatan model hexapod robot dengan cara jalan robot menggunakan model one wave, two wave, dan tripod, maka diperoleh hasil kecepatan yang ditunjukkan pada Gambar 15 [8].

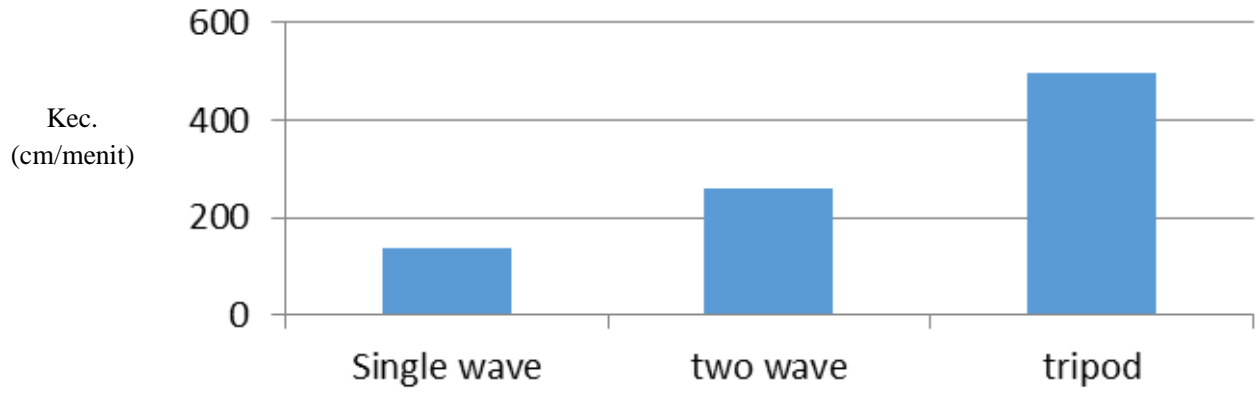

Gambar 15. Grafik hasil pengujian kecepatan

Selanjutnya berdasarkan Gambar 15 didapatkan nilai rata-rata kecepatan dalam mencapai jarak $100 \mathrm{~cm}$ yaitu $136,7 \mathrm{~cm} /$ menit untuk tipe gerak one wave; $260,87 \mathrm{~cm} /$ menit untuk tipe gerak berjalan two wave; dan 495,46 cm/menit untuk tipe gerak berjalan tripod.

\subsection{Pengujian Konsumsi Daya}

Pengujian konsumsi daya dilakukan untuk mengetahui laju konsumsi daya oleh hexapod robot ketika sedang bergerak. Pengujian ini dilakukan dengan mengukur laju arus pada sistem robot pada kondisi robot benar-benar berjalan kemudian diambil nilai rataannya. Pengukuran dilakukan dengan alat ampere meter dengan titik bacaan adalah keluaran dari baterai. Dengan demikian, ketika robot beroperasi dapat terukur laju arus listrik yang bekerja pada sistem robot untuk kemudian menghitung daya (W). Ampere meter yang digunakan untuk pengambilan data arus pada hexapod robot membaca nilai arus setiap 0,5 detik. Dan pada pengujian ini diambil 10 data sample tiap jenis gerak robot untuk diambil nilai rataannya. Hasil pengujian konsumsi daya model hexapod robot yang telah dirata-rata ditunjukkan pada Gambar 16.

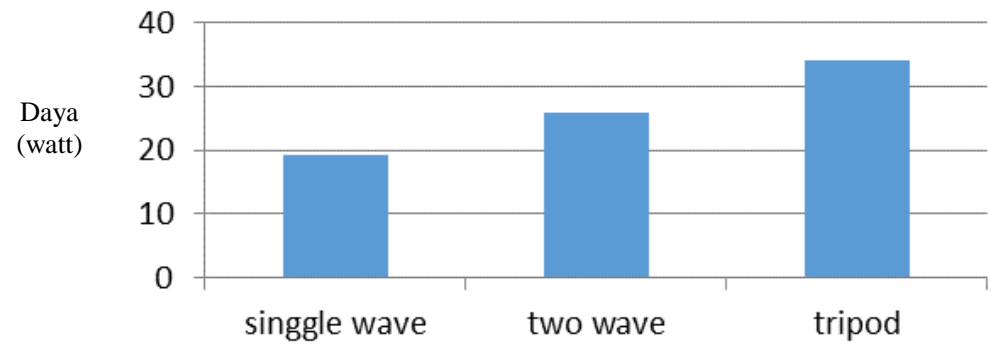

Gambar 16. Grafik hasil pengujian konsumsi daya

\subsection{Sistem Monitoring}

Model hexapod robot ini akan digunakan untuk sistem monitoring keamanan dimana pada pengaplisiannya robot akan berjalan dan mengambil sekaligus mengirimkan data visual. Robot cukup dioperasikan oleh operator dari jarak jauh secara nirkabel dari home base ke suatu tempat yang lain yang menjadi target untuk dipantau seperti yang diilustrasikan pada Gambar 17. Dari ilustrasi tersebut dapat dilihat bahwa robot berjalan dan mengambil data visual dari gedung A, kemudian mengirimkannya kepada operator yang mengendalikan robot dari gedung B (home base) secara nirkabel. Dengan demikian, robot dapat berfungsi sebagai surveillance robot untuk sistem monitoring keamanan yang meminimalkan kasus pencurian atau hal lainnya di suatu area. 


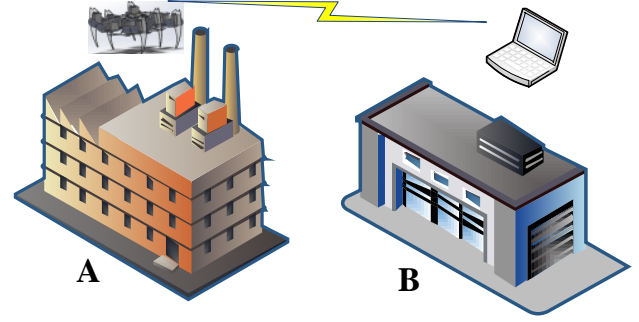

Gambar 17. Ilustrasi aplikasian hexapod robot

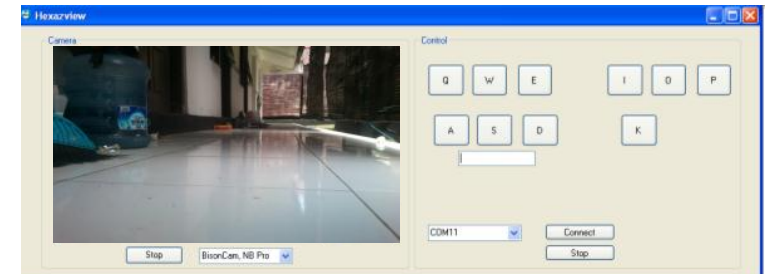

Gambar 18. Pengambilan gambar pada model hexapod robot user interface

Selanjutnya agar aplikasi dapat memudahkan operator pengguna, maka dibuat sebuah user interface atau antarmuka yang berfungsi sebagai pusat kendali dan penerimaan data visual yang dikirim oleh robot dan ditunjukkan pada Gambar 18. User interfece ini menyajikan tampilan visual kondisi di sekitar robot yang ditangkap oleh kamera dan dikirim secara nirkabel, dimana tombol pada keyboard komputer digunakan untuk mengontrol gerak robot serta mengubah arah kamera. Adapun fungsi masing-masing tombol telah didefiniskan untuk menggerakkan robot ke kiri, kanan, mundur, maju, rotasi, maupun arah kamera ke atas, bawah, kanan, kiri, dan lain-lain. Untuk mengoperasikan user interface ini yang pertama dilakukan adalah menghubungkan modul wireless serial dan kamera. Setelah semua terhubung, pada interface sebelah bawah kolom kamera kita pilih kamera yang terhubung, lalu klik tombol start dan visualisasi dari kamera akan tersaji pada jendela yang tersedia. Kemudian di sebelah kanan user interface kita pilih COM yang terhubung untuk komunikasi serial, kemudian klik tombil connect dan start maka robot sudah terhubung dan dapat dikendalikan melalui user interface.

\section{KESIMPULAN}

Pada penelitian ini berhasil dibuat model snooper hexapod robot dengan bahan akrilik dengan aktuator servomotor dan mikrokontroler ATmega128 yang digunakan untuk sistem monitoring suatu area dimana kondisi visual area yang dimonitor dikirimkan secara nirkabel ke home base. Model hexapod robot dianalisa forward dan inverse kinematics dan menunjukkan tingkat error yang kecil antara hasil perhitungan dengan pengujian. Selain itu dilakukan juga perhitungan forward dan inverse dynamic menggunakan MatLab Simmechanics untuk memperoleh nilai torsi berdasarkan trajektory yang digunakan. Adapun jenis gerakan berjalan robot mempunyai kelebihan dan kekurangannya masing-masing, dimana jenis tripod yang memiliki kecepatan tertinggi, namun juga memiliki error yang paling besar serta konsumsi daya yang besar pula. Berbanding terbalik dengan jenis gerakan onewave yang paling lambat namun memiliki error terkecil dan konsumsi daya paling rendah.

\section{REFERENSI}

[1] Pa, P.S., Wu, C.M., 2012, "Design of a hexapod robot with a servo control and a man-machine interface," Robotics and Computer-Integrated Manufacturing, 28: 351-358.

[2] K. Dempsey, N.S. Chawla, A. Johnson, A.C. Jones, A. Orebaugh, M. Scholl, K. Stine, 2011, "Information security continuous monitoring (ISCM) for federal information systems and organizations", National Institute of Standards and Technology U.S. Department of Commerce, NIST Special Publication, 800-137.

[3] Wang, Z., Ding, X., Rovetta, A., Glusti, A., 2011, Mobility Analysis of the Typical Gait of a Radial Symmetrical Six-Legged Robot, Mechatronics, 21 (7): 1133-1146.

[4] De Santos, P.G., Garcia, E., Estremera, J., 2005, "Quadrupedal Locomotion: An Introduction to the Control of Four-Legged Robots," Springer, Spain.

[5] Craig, J.J., 1989, "Introduction to Robotics Mechanics and Control $2^{\text {nd }}$ Edition," Addition-Wesley Publishing Company, USA, 76-84.

[6] Elang, P.P., 2013, “ Pemodelan dan Analisa Kinematik Dinamik Snooper Hexapod Robot, Tugas Akhir Sajana.

[7] Oricom Technologies, Juni 2003, Analysis of Multi-Legged Animal + Robot Gaits, http://www.oricomtech.com/projects/leg-time.htm, diakses tanggal 19 September 2013 jam 10.30 WIB.

[8] Jalu, R. M., 2013, “ Rancang Bangun dan Uji Gerak Berjalan Snooper Hexapod Robot untuk Sistem Keamanan, Tugas Akhir Sarjana. 